OPEN ACCESS

Edited by:

Virginio Salvi,

ASST Fatebenefratelli Sacco, Italy

Reviewed by: Karl Bechter

University of UIm, Germany

Giuseppe Carrà,

Università degli studi di Milano

Bicocca, Italy

*Correspondence:

Benjamin I. Goldstein

benjamin.goldstein@sunnybrook.ca

Specialty section:

This article was submitted to

Psychosomatic Medicine,

a section of the journal

Frontiers in Psychiatry

Received: 31 October 2018 Accepted: 08 January 2019 Published: 29 January 2019

Citation:

Toma S, Fiksenbaum L, Omrin D and Goldstein BI (2019) Elevated Familial Cardiovascular Burden Among Adolescents With Familial Bipolar Disorder. Front. Psychiatry 10:8. doi: 10.3389/fpsyt.2019.00008

\section{Elevated Familial Cardiovascular Burden Among Adolescents With Familial Bipolar Disorder}

\author{
Simina Toma ${ }^{1,2}$, Lisa Fiksenbaum ${ }^{1}$, Danielle Omrin ${ }^{1}$ and Benjamin I. Goldstein ${ }^{1,2,3 *}$ \\ ${ }^{1}$ Centre for Youth Bipolar Disorder, Sunnybrook Health Sciences Centre, Toronto, ON, Canada, ${ }^{2}$ Department of Psychiatry, \\ University of Toronto, Toronto, ON, Canada, ${ }^{3}$ Department of Pharmacology, University of Toronto, Toronto, ON, Canada
}

Background: Bipolar disorder (BD) is one of the most heritable medical conditions, and certain phenotypic characteristics are especially familial in BD. BD is also strongly associated with elevated and premature cardiovascular disease (CVD) morbidity and mortality. Thus, far, little is known regarding the familiality of cardiovascular risk in BD. We therefore examined the extent of CVD-related conditions among relatives of: adolescents with $\mathrm{BD}$ with a family history of $\mathrm{BD}$ (familial $\mathrm{BD}$ ), adolescents with $\mathrm{BD}$ without a family history of BD (non-familial BD) and healthy controls $(\mathrm{HC})$.

Materials and Methods: The sample included 372 adolescents; 75 with familial BD, 96 with non-familial BD, and $201 \mathrm{HC}$. Parents of the adolescents completed the CARDIA Family Medical History interview regarding the adolescents' first- and second- degree adult relatives. We computed a "cardiovascular risk score" (CRS) for each relative, based on the sum of the presence of diabetes, hypertension, obesity, dyslipidemia, stroke, angina, and myocardial infarction (range 0-7). Primary analyses examined for group differences in mean overall CRS scores among first and second- degree relatives combined, controlling for age, sex, and race. Secondary analyses examined first- and second-degree relatives separately, controlling for age, sex, and race.

Results: There were significant between-group differences in CRS in first- and second- degree relatives combined, following the hypothesized ordering: CRS was highest among adolescents with familial BD (1.14 \pm 0.78$)$, intermediate among adolescents with non-familial $\mathrm{BD}(0.92 \pm 0.79)$ and lowest in $\mathrm{HC}(0.76 \pm 0.79 ; F=6.23$, $\left.d f=2, p=0.002, \eta_{p}^{2}=0.03\right)$. There was a significant pairwise difference between adolescents with familial BD and $\mathrm{HC}(p=0.002$, Cohen's $d=0.49)$. A similar pattern of between-group differences was identified when first-degree and second-degree relatives were examined separately.

Limitations: familial cardiovascular burden was determined based on parent interview, not evaluated directly.

Conclusions: Adolescents with BD with a family history of BD have elevated rates of CVD-related conditions among their relatives. This may be related to genetic overlap between $\mathrm{BD}$ and CVD-related conditions, shared environmental factors that contribute to both $\mathrm{BD}$ and $\mathrm{CVD}$-related conditions, or a combination of these factors. More research is warranted to better understand the interaction between familial risk for BD and CVD, and to address this risk using family-wide preventive approaches.

Keywords: bipolar, metabolic, family history, cardiovascular, adolescents 


\section{INTRODUCTION}

Bipolar Disorder (BD) is a chronic mood disorder with a strong genetic contribution (1). Studies have estimated that heritability of $\mathrm{BD}$ is 0.8 , although the exact pattern of heritability and implicated genes are not yet elucidated (2). In addition to an 8-20 fold increase in risk of developing $\mathrm{BD}$, relatives of those with $\mathrm{BD}$ are at higher risk for other psychiatric conditions such as depressive disorders, anxiety disorders, attention deficit hyperactivity disorder (ADHD), and substance use disorders (3, 4). Studies have also reported neurocognitive differences between unaffected relatives of $\mathrm{BD}$ probands and controls, potentially related in part to obesity in the unaffected relatives (5-7). Furthermore, in those with $\mathrm{BD}$ with a family history of $\mathrm{BD}$ (familial BD), several characteristics, and markers of severity such as substance use disorders, psychosis, suicidality, and level of social functioning may be shared by $\mathrm{BD}$ probands from the same family, suggesting that certain phenotypes may congregate in familial BD (8).

There is a known link between BD and cardiovascular disease (CVD) risk, with excessive and premature morbidity and mortality replicated in samples from various countries (915). CVD and its complications are the leading cause of mortality in $\mathrm{BD}$, and the most common medical conditions in $\mathrm{BD}(16,17)$. In comparison to healthy controls (HC) individuals with $\mathrm{BD}$ have an adjusted CVD mortality rate ratio of 1.5-2.5 and CVD mortality 10 years earlier than in the general population $(16,18)$. In addition, the age of onset of new CVD was found to be up to 17 years premature in BD (19). Metabolic syndrome and its components of obesity, hypertension, high cholesterol levels and type II diabetes are also elevated in those with BD (20-22). This association between CVD and $\mathrm{BD}$ is in excess of what can be explained by psychotropic medication, lifestyle behaviors and even traditional CVD risk factors $(11,19,23-25)$.

There is a paucity of studies on the topic of cardiovascular burden in unaffected relatives of $\mathrm{BD}$ probands. One study found lower plasma high-density lipoprotein (HDL) cholesterol and increased omega- 6 fatty acids in adult unaffected first-degree relatives of adults with $\mathrm{BD}$ in comparison to controls (26). A second study found increased prevalence of cardiovascularrelated conditions (diabetes, hypertension, hyperlipidemia, and coronary artery disease) with a risk rate ratio of 4.8 in affected and unaffected adult first-degree relatives of probands with schizophrenia, schizoaffective disorder, bipolar subtype, and $\mathrm{BD}$ with psychotic symptoms in comparison to controls (27). Adult offspring of $\mathrm{BD}$ subjects were included. There was no effect of the specific psychiatric diagnosis of the proband on cardiovascular risk in the relative (27). A third study examining first-, secondand third-degree relatives of subjects with $\mathrm{BD}$ within a large extended family did not find differences in the rate of metabolic syndrome or obesity rates in $\mathrm{BD}$ relatives vs. HC, but found higher total cholesterol, LDL and triglycerides, lower HDL, and abnormal glucose in BD relatives (28). An analysis of children and adolescents with a second- or third-degree family history of $\mathrm{BD}$ (mean age 11.6 years old) in contrast to HC (mean age 7.8 years old), controlling for age, found higher rates of elevated LDL in the BD relatives than in $\mathrm{HC}$, although there were higher rates of elevated triglycerides and low HDL in the HC group (28).

Importantly, there is a strong familial aggregation of metabolic syndrome and its components in non-psychiatric samples (2931). A large study in psychiatrically healthy young adults found anomalous blood pressure (BP), cholesterol and glucose profiles in those with parental history of CVD-related conditions including myocardial infarction, stroke, diabetes, hypertension and obesity (32). In the only study on the topic, a family history of type II diabetes was associated with metabolic abnormalities such as insulin resistance, fasting blood glucose, higher body mass index (BMI), and waist circumference in adult women with $\mathrm{BD}$, and the impact of a family history of type II diabetes was greater in those with $\mathrm{BD}$ than in controls (33).

Given the paucity of research on this important topic, particularly in relation to early-onset $\mathrm{BD}$, we compared the cardiovascular burden among adolescents, and hypothesized that cardiovascular burden would be highest among adolescents with familial BD, followed by adolescents with non-familial BD, followed by $\mathrm{HC}$ adolescents.

\section{MATERIALS AND METHODS}

This study included 372 adolescent participants (171 BD, 201 HC) between the ages of 13-20 years old. Adolescents with BD-I, -II, or -Not Otherwise Specified (NOS) were recruited from a tertiary subspecialty clinic in an academic health sciences center in Toronto, Canada, and HC were recruited from the community via advertisements in the Greater Toronto Area. All participants were English-speaking. HC had no lifetime history of mood or psychotic disorders, or substance use disorders within the preceding 3 months. In addition, $\mathrm{HC}$ did not have a first- or second-degree family history of $\mathrm{BD}$ or psychotic disorders. HC were also excluded if they had a history of cardiac, autoimmune or inflammatory illness, neurological or cognitive impairment or were treated with anti-inflammatory, anti-platelet, anti-lipidemic, anti-hypertensive, or hypoglycemic agents including insulin and metformin.

Adolescent psychiatric diagnoses were made using the Schedule for Affective Disorders and Schizophrenia for School Age Children, Present, and Life Version (K-SADS-PL) (34), a semi-structured interview completed with adolescents and parents to ascertain current and lifetime history of psychiatric disorders. The KSADS Depression Rating Scale (DRS) (35) and the KSADS Mania Rating Scale (MRS) (36) were used in place of the mood section in the K-SADS-PL. Diagnoses were confirmed by a child-adolescent psychiatrist. BD-NOS was defined using criteria previously operationalized by the Course and Outcome of Bipolar Illness in Youth (COBY) study group (37): Elevated and/or irritable mood, plus (1) two Diagnostic and Statistical Manual of Mental Disorders, 4th ed. (DSM-IV) (38) manic symptoms (3 if only irritable mood is reported), (2) change in functioning, (3) mood, and symptom duration of at least $4 \mathrm{~h}$ during a $24 \mathrm{~h}$ period, and (4) at least four cumulative $24 \mathrm{~h}$ periods of episodes over the participants' lifetime that meet the mood, symptom severity, and functional change criteria. Overall, the 
participants' general level of functioning was evaluated using the Children's Global Assessment Scale (CGAS) (39), which was administered as an interview. Socio-economic Status (SES) was evaluated using the Hollingshead Four Factor Index (40).

Family psychiatric history in all first- and second-degree relatives was evaluated using the Family History Screen interview (41). The Coronary Artery Risk Development in Young Adults Study (CARDIA) Family Medical History was completed as an interview with adolescents and their parents, regarding adolescents' first- and second-degree adult relatives (42). Adolescents and a parent were interviewed and provided information on second-degree relatives of the adolescent, including aunts, uncles and grand-parents. These second-degree relatives were not directly interviewed, nor were their medical records accessed. The current study focused on family history of diabetes, hypertension, obesity, dyslipidemia, stroke, angina, and myocardial infarction. A "Cardiovascular Risk Score" (CRS) was computed for each relative based on the sum of the number of these conditions present (score of $0-7$ ). Given the young age of participants' siblings, first-degree relatives included only parents. Familial mean CRS scores were calculated for parents and for combined first- and second-degree relatives.

All participants, as well as one parent or guardian, provided written informed consent prior to study participation. The study was approved by the local research ethics board.

\section{Anthropomorphic Variables}

Measures of height and weight were available for 339 adolescents, and systolic blood pressure (SBP) and diastolic blood pressure (DBP) were available for 344 adolescents. Body mass index (BMI) was computed by dividing weight in kilograms $(\mathrm{kg})$ by height in meter squared $\left(\mathrm{m}^{2}\right)$ as previously described (43). Percentiles were determined using the BMI-for-age percentile based on Centers for Disease Control (CDC) growth charts, applicable for youth under the age of 20 (44).

\section{Statistical Analysis}

Analyses were performed using SPSS, version 24 (IBM Corp., Armonk, N.Y., USA). Participants were divided into three groups: BD adolescents with family history of BD (familial BD), $\mathrm{BD}$ adolescents without family history of BD (non-familial BD), and $\mathrm{HC}$ adolescents. Group differences were evaluated using one-way ANOVA for dimensional measures and chi-square tests for dichotomous measures. To test our primary hypothesis, a one-way ANCOVA (controlling for age, sex, and race) was used to compare CRS across the three groups. Omnibus tests comparing CRS across the groups were followed by post-hoc pairwise comparisons of CRS.

\section{RESULTS}

\section{Demographic and Clinical Characteristics}

Table 1 presents demographic and clinical variables for all study participants; descriptive statistics are presented for $\mathrm{BD}$ participants in Table 2. The sample included 372 adolescents: 75 with familial BD, 96 with non-familial BD, and 201 HC. 372 parents were interviewed (one for each adolescent participant) and provided information regarding their own medical history along with that of co-parents and second-degree relatives. In total, information regarding medical history was obtained regarding 2,797 second degree relatives, among which 561 were relatives of adolescents with familial BD, 691 were relatives of adolescents with non-familial $\mathrm{BD}$, and 1,545 were relatives of healthy adolescents. There were significant differences between the adolescent groups in terms of age, sex, and race. A total of $19.9 \%$ of the HC group had at least one lifetime psychiatric diagnosis, including anxiety disorders (8.5\%), ADHD (11.1\%), obsessive compulsive disorder (OCD; 1\%), and oppositional defiant disorder (ODD; 1\%). Furthermore, $1 \%$ of $\mathrm{HC}$ had a lifetime history of antidepressant use, and $4 \%$ had a lifetime history of stimulant use.

Anthropomorphic variables are presented in Table 3. There were significant between-group differences in BMI percentile $\left(F=4.40, p=0.01, \eta_{\mathrm{p}}^{2}=0.03\right)$. When controlling for age, sex and race, average systolic, and average diastolic BP were also significantly higher in the $\mathrm{BD}$ groups in comparison to $\mathrm{HC}$ (respectively $F=4.85, p=0.008, \eta_{\mathrm{p}}^{2}=0.03 ; F=6.86, p<0.001$, $\left.\eta_{\mathrm{p}}^{2}=0.04\right)$.

\section{Cardiovascular Risk Score (CRS)}

Overall familial CRS (i.e., first and second-degree relatives combined) differed significantly across groups in the hypothesized direction: highest among familial BD (1.14 \pm 0.78), intermediate among non-familial $\mathrm{BD}(0.92 \pm 0.79)$, and lowest among HC $(0.76 \pm 0.79)$ (see Table 2$)(F=6.23$, $\left.p=0.002, \eta_{\mathrm{p}}^{2}=0.03\right)$. Planned pair-wise comparisons indicated a significant difference between the familial BD and HC groups ( $p=0.002$, Cohen's $d=0.49$ ), and non-significant differences between the familial BD and non-familial BD relatives $(p=0.19$; Cohen's $d=0.28$ ) as well as between the non-familial BD and HC relatives ( $p=0.34$; Cohen's $d=0.20)$.

CRS among only first-degree relatives (i.e., parents) followed the same pattern: highest among familial BD (0.65 \pm 0.60$)$, intermediate among non-familial BD $(0.48 \pm 0.60)$, and lowest among HC (0.32 \pm 0.61$)$ (see Table 2$)(F=8.63, p<0.001$, $\left.\eta_{\mathrm{p}}^{2}=0.05\right)$. Planned pair-wise comparisons indicated a significant difference between familial $\mathrm{BD}$ and $\mathrm{HC}(p<0.001$; Cohen's $d=0.56)$ but not between familial $\mathrm{BD}$ and non-familial $\mathrm{BD}$ ( $p=0.11$; Cohen's $d=0.30)$ or between non-familial BD and HC $(p=0.15$; Cohen's $d=0.26)$.

Finally, CRS among only second-degree relatives also followed the same pattern: highest among familial BD (0.67 \pm 0.47$)$, intermediate among non-familial BD $(0.57 \pm 0.47)$, and lowest among HC (0.49 \pm 0.48$)$ (see Table 2$)(F=3.96, p=0.02$, $\left.\eta_{\mathrm{p}}^{2}=0.02\right)$. Planned pair-wise comparisons indicated a significant difference between familial BD and $\mathrm{HC}(p=0.02$, Cohen's $d=0$. 38 ) but not between familial BD and non-familial BD $(p=0.45$, Cohen's $d=0.21)$ or between non-familial BD and HC ( $p=0.58$, Cohen's $d=0.17$ ).

\section{DISCUSSION}

This study found that cardiovascular risk, based on a score defined by the combination of diabetes, hypertension, obesity, 
TABLE 1 | Demographic and clinical variables among 372 adolescents.

\begin{tabular}{|c|c|c|c|c|c|c|}
\hline & \multicolumn{3}{|c|}{ Participants } & \multicolumn{3}{|c|}{ Statistics } \\
\hline & Familial BD $(n=75)$ & Non-familial BD $(n=96)$ & HC $(n=201)$ & $F / \chi^{2}$ & Cramer's V/ $\eta p^{2}$ & $P$-value \\
\hline Age, years $( \pm S D)$ & $16.5 \pm 1.46$ & $16.8 \pm 1.50$ & $16 \pm 1.82$ & 7.68 & 0.04 & $<0.001$ \\
\hline Females (\%) & 48 (64\%) & $66(68.8 \%)$ & 104 (51.7\%) & 8.88 & 0.15 & 0.012 \\
\hline Race (\%Caucasian) & 63 (84\%) & 75 (78.1\%) & $112(55.7 \%)$ & 26.82 & 0.27 & $<0.001$ \\
\hline SES ( $\pm S D)$ & $49.19 \pm 12.08$ & $48.95 \pm 14.18$ & $52.36 \pm 11.13$ & 3.41 & 0.02 & 0.034 \\
\hline
\end{tabular}

BD, Bipolar Disorder; HC, Healthy Controls; SES, Socio-economic Status; SD, Standard Deviation.

\begin{tabular}{lc}
\hline TABLE 2 | Clinical characteristics among 171 adolescents with bipolar disorder. \\
\hline Age at onset ( \pm SD) & $14.66 \pm 2.73$ \\
BD subtype (\%) & \\
BD-I & $45(26.3 \%)$ \\
BD-II & $65(38 \%)$ \\
BD-NOS & $61(35.7 \%)$ \\
Lifetime comorbidity (\%) & \\
Substance use disorder & $59(35.5 \%)$ \\
ADHD & $79(47.6 \%)$ \\
Anxiety disorder & $132(79.5 \%)$ \\
OCD & $29(17.5 \%)$ \\
ODD & $54(32.5 \%)$ \\
Lifetime medication use (\%) & \\
SGA & $92(55.4 \%)$ \\
Lithium & $28(16.9 \%)$ \\
Antimanic/Anticonvulsant & $13(7.8 \%)$ \\
Antidepressant (SSRI) & $62(37.3 \%)$ \\
Stimulants & $37(22.3 \%)$ \\
Clinical scores ( \pm SD) & \\
Mania score-current & $18.43 \pm 12.44$ \\
Mania score-lifetime most severe & $29.60 \pm 9.05$ \\
Depression score-lifetime most severe & \\
CGAS-Current episode & $51.59 \pm 10.21$ \\
CGAS-Highest past & $52.99 \pm 10.57$ \\
CGAS-Lowest past & $42.29 \pm 8.73$ \\
\hline DDD score-current & \\
\hline
\end{tabular}

ADHD, Attention Deficit/Hyperactivity Disorder; BD, Bipolar Disorder; CGAS, Children's Global Assessment Scale; OCD, Obsessive Compulsive Disorder; ODD, Oppositional Defiant Disorder; SD, Standard Deviation; SGA, Second Generation Antipsychotics; SSRI, Selective Serotonin Reuptake Inhibitor.

dyslipidemia, stroke, angina, and myocardial infarction, was highest in relatives of adolescents with familial $\mathrm{BD}$, followed by relatives of adolescents with non-familial $\mathrm{BD}$, followed by relatives of $\mathrm{HC}$ adolescents. Whereas, familial CRS differed significantly between adolescents with familial $\mathrm{BD}$ and $\mathrm{HC}$, familial CRS among adolescents with non-BD did not differ significantly from the other groups. A similar pattern, including the ordering effect and between-group effect sizes, was found for combined first- and second-degree relatives, and for first- and second- degree relatives examined separately.

In addition to the known link between BD and cardiovascular risk, the limited number of prior studies on the topic of cardiovascular burden in adult $\mathrm{BD}$ relatives also found elevated rates of dyslipidemia and insulin resistance, including those unaffected by $\mathrm{BD}$, in comparison to $\mathrm{HC}$ relatives $(20,26-28)$. The current study extends prior findings by showing that relatives of adolescents with $\mathrm{BD}$ have particularly elevated cardiovascular risk in the context of a family loading of $\mathrm{BD}$, which has not been previously described. Relatives of adolescents with non-familial BD were intermediate between the other groups. This ordering effect could reflect differential loading of genetic and/or environmental risk for CVD-related conditions. Our findings could be due to familial $\mathrm{BD}$ being a more severe phenotype, shared genetic factors or biological processes such as inflammation, familial psychiatric burden, or environmental influences such as patterns of exercise and substance use (45-48). However, the current study was not designed to evaluate these hypotheses.

Family history of BD or other mood disorders has been associated with an earlier age of onset of $\mathrm{BD}$, higher rates of psychiatric comorbidities and an overall more severe course of illness among people with $\mathrm{BD}(8,45,49,50)$. More severe course of $\mathrm{BD}$, in turn, is associated with increased risk of CVD and CVD mortality (19, 51-53). Relatedly, prior cross-sectional studies found that CVD risk factors, including metabolic syndrome and its components, are associated with increased functional impairment, suicide attempts and symptom severity in BD (54-56). Taking together prior findings and current findings, it appears that there is an interweaving of psychiatric and cardiovascular burden in $\mathrm{BD}$, and that this interweaving is familial.

Prior studies provide context for the potential genetic contributions to current findings. Independently, BD and metabolic syndrome are each known to have a strong familial aggregation, yet little is known about their interaction (1, 2931). A study found that susceptibility gene TCF7L2 conferred an increased risk of BD in the presence of elevated BMI, suggesting an interaction between an interaction between obesity and BD risk (57). Furthermore, genetic variants thought to be implicated in BD such as BDNF, MTHFR, GNAS, and CACNA1C/D, have been hypothesized to overlap between BD and CVD, conferring risk of mood disorders in addition to risk of hypertension, type 2 diabetes, obesity, and dyslipidemia $(46,58)$. Dysregulation of the inflammatory system with increased pro-inflammatory markers such as cytokines, especially during acute mood episodes has been well-described in BD, and may comprise a familial trait in BD pedigrees (59-63). 
TABLE 3 | Anthropomorphic variables among adolescents.

\begin{tabular}{|c|c|c|c|c|c|c|}
\hline & \multicolumn{3}{|c|}{ Participants } & \multicolumn{3}{|c|}{ Statistics } \\
\hline & Familial BD & Non-familial BD & $\mathrm{HC}$ & $F / \chi^{2}$ & Cramer's V/ $\eta p^{2}$ & $P$-value \\
\hline $\begin{array}{l}\text { BMI percentile } \\
(n=336)\end{array}$ & $\begin{array}{c}62.67 \pm 27.67 \\
(n=65)\end{array}$ & $\begin{array}{c}66.07 \pm 26.08 \\
(n=77)\end{array}$ & $\begin{array}{c}56.01 \pm 26.88 \\
(n=194)\end{array}$ & 4.4 & 0.03 & 0.013 \\
\hline $\begin{array}{l}\text { Systolic blood pressure } \\
(n=344)\end{array}$ & $\begin{array}{c}115.70 \pm 19.07 \\
(n=67)\end{array}$ & $\begin{array}{c}114.72 \pm 16.44 \\
(n=79)\end{array}$ & $\begin{array}{c}110.04 \pm 13.63 \\
(n=198)\end{array}$ & 4.85 & 0.03 & 0.008 \\
\hline $\begin{array}{l}\text { Diastolic blood } \\
\text { pressure } \\
(n=344)\end{array}$ & $\begin{array}{c}72.75 \pm 9.40 \\
(n=67)\end{array}$ & $\begin{array}{c}70.87 \pm 11.01 \\
(n=79)\end{array}$ & $\begin{array}{c}67.5 \pm 7.68 \\
(n=198)\end{array}$ & 6.86 & 0.04 & 0.001 \\
\hline
\end{tabular}

BD, Bipolar Disorder; HC, Healthy Controls; SES, Socio-economic Status; SD, Standard Deviation.

It is well-recognized that immune dysfunction and chronic inflammation are associated with CVD and related risk factors (64-66). It has been proposed that a genetic predisposition to inflammation could be linked to both $\mathrm{BD}$ and CVD-related conditions (67).

Similar to putative genetic contributions, prior studies also provide context for the potential environmental contributions to current findings. For example, obesity and metabolic syndrome have been associated with pregnancy complications such as gestational hypertension or preeclampsia, as well as future risk of obesity and heart disease in the offspring $(68,69)$. Maternal cardiovascular risk factors during pregnancy have been linked with an increased risk of ADHD, autism spectrum disorder, eating disorders, and psychosis in offspring $(70,71)$. Although studies have yet to link maternal gestational cardiovascular risk factors with risk of BD in offspring, it is known that these risk factors are increased among pregnant women with $\mathrm{BD}$, which one can speculate is also relevant to the transmission of $\mathrm{BD}$ to the offspring, and to the cross-risk of CVD-related conditions and $\mathrm{BD}(72)$.

Another environmental factor that may underlie our findings is lifestyle. For example, an individual's physical activity is associated with physical activity among relatives $(73,74)$ and some studies have found that adults with BD tend to be less physically active than the general population (75-79). Similarly, there is also evidence that adolescents with $\mathrm{BD}$ are less likely to engage in moderate-vigorous physical activity than controls (80). Sedentary lifestyle has been associated in the general population with metabolic syndrome and CVD morbidity and mortality (47, 81). While there are genetic factors that contribute to physical activity, reduced physical activity in relatives also comprises an environmental factor that influences behavior $(82,83)$. Similar considerations apply to other CVD risk factors such as cigarette smoking (84-87). Furthermore, adverse childhood experiences such as poverty, family conflicts, maltreatment, neglect, or peer victimization have been linked with both cardiovascular burden and psychopathology, and this association is thought to be mediated by both psychological and neurobiological factors $(11,88,89)$ Indeed, there is a hypothesized synergistic interaction between genetic predisposition, epigenetic factors such as DNA methylation in the presence of early adversity, health behaviors and subsequent risk for mood disorders and CVD (88, 90-92).

\section{LIMITATIONS}

Several limitations may have impacted our findings. First, the data collected from adolescents and their parents is indirect and based on their knowledge of family history. The absence of direct assessment of the relatives' cardiovascular health or access of their medical records is a major limitation of this study. Future studies would benefit from directly examining medical records and directly evaluating for psychiatric disorders and directly measuring cardiovascular risk factors. Given known disparities in the recognition and treatment of CVD-related conditions among people with $\mathrm{BD}$ and other severe psychiatric conditions, our findings may be biased toward lower CRS scores. Second, although we have controlled for key demographic variables, the study methods and sample size do not allow us to address questions regarding the effect of $\mathrm{BD}$ independent of variables such as psychiatric comorbidities and lifestyle. Nonetheless, prior epidemiologic studies in predominantly untreated samples have verified that the BD-CVD link is independent of these important considerations $(19,25)$. Finally, the CRS was computed as a sum score of conditions that are inter-related, and includes cardiovascular risk factors (e.g., hypertension) alongside fully manifest vascular disorder (e.g., myocardial infarction). Larger samples would enable alternative proxies for cardiovascular burden, and would allow for evaluation of fully manifest vascular disorder while controlling for cardiovascular risk factors (as has been done in studies evaluating cardiovascular risk among those with BD). Counter-balancing these limitations is the importance of gaining insights regarding the BD-CVD link; to this end, the current study is the first on the topic that is focused on adolescents, and the first study in any age group to evaluate the link between familiality of BD and familiality of cardiovascular risk.

\section{FUTURE DIRECTIONS}

In addition to the aforementioned future directions within the limitations section, studies are warranted that examine for correlation between probands and their relatives regarding cardiovascular burden, and that evaluate whether these correlations differ across groups (i.e., familial BD, non-familial $\mathrm{BD}, \mathrm{HC})$. Because of the very large samples required to evaluate low-frequency "hard" endpoints, such as myocardial 
infarction and stroke, administrative database studies based on large population samples would provide complementary information to that available in clinical cohort studies. As with any observational study, prospective design would offer advantages with regard to causal inferences and mechanisms. Studies that include genetic markers and biomarkers beyond glucose and lipids (e.g., inflammatory markers, neurotrophic factors, oxidative stress markers) would enable further evaluation of potential bridges linking $\mathrm{BD}$ and CVD-related conditions. Finally, it will be important to move toward modifying assessment and treatment approaches that are informed by the BD-CVD link. For example, treatment approaches for those with $\mathrm{BD}$ may benefit from the assessment of medical and psychiatric family history and identification of those at higher risk. In addition, future studies evaluating behavioral and pharmacological approaches to prevention and treatment of CVD-related conditions in BD could benefit from incorporating familial considerations.

\section{CONCLUSIONS}

In conclusion, we found that adolescents with $\mathrm{BD}$ with a family history of $\mathrm{BD}$ have elevated rates of CVD-related conditions among their relatives. This may be related to genetic overlap between $\mathrm{BD}$ and CVD-related conditions, shared environmental factors that contribute to both BD and CVDrelated conditions, or a combination of these factors. More research is warranted to better understand the interaction between familial risk for $\mathrm{BD}$ and CVD. The possible interaction between $\mathrm{BD}$ familial loading and CVD loading opens the opportunity to integrate familial medical and psychiatric history

\section{REFERENCES}

1. Goodwin FK, Jamison K. Manic-Depressive Illness: Bipolar Disorders and Recurrent Depression. 2nd ed. New York, NY: Oxford University Press (2007).

2. Fullerton JM, Koller DL, Edenberg HJ, Foroud T, Liu H, Glowinski AL, et al. Assessment of first and second degree relatives of individuals with bipolar disorder shows increased genetic risk scores in both affected relatives and young At-Risk Individuals. Am J Med Genet Part B Neuropsychiatr Genet. (2015) 168:617-29. doi: 10.1002/ajmg.b.32344

3. DelBello MP, Geller B. Review of studies of child and adolescent offspring of bipolar parents. Bipolar Disord. (2001) 3:325-34. doi: 10.1034/j.1399-5618.2001.30607.x

4. Mortensen PB, Pedersen CB, Melbye M, Mors O, Ewald H. Individual and familial risk factors for bipolar affective disorders in Denmark. Arch Gen Psychiatry (2003) 60:1209-15. doi: 10.1001/archpsyc.60.12.1209

5. Frangou S, Haldane M, Roddy D, Kumari V. Evidence for deficit in tasks of ventral, but not dorsal, prefrontal executive function as an endophenotypic marker for bipolar disorder. Biol Psychiatry (2005) 58:838-9. doi: 10.1016/j.biopsych.2005.05.020

6. Lin $\mathrm{K}, \mathrm{Lu} \mathrm{R}$, Chen $\mathrm{K}, \mathrm{Li} \mathrm{T}, \mathrm{Lu} \mathrm{W}$, Kong J, et al. Differences in cognitive deficits in individuals with subthreshold syndromes with and without family history of bipolar disorder. J Psychiatr Res. (2017) 91:177-83. doi: 10.1016/j.jpsychires.2017.05.005

7. McIntyre RS, Mansur RB, Lee Y, Japiassú L, Chen K, Lu R, et al. Adverse effects of obesity on cognitive functions in individuals at ultra high risk for bipolar disorder: results from the global mood and brain science initiative. Bipolar Disord. (2017) 19:128-34. doi: 10.1111/bdi.12491 during assessment, and opens the opportunity to use this information to inform prevention and treatment strategies. Involvement of family members may be beneficial due to the shared environmental factors and familial nature of BD and cardiovascular risk.

\section{ETHICS STATEMENT}

Sunnybrook Health Sciences Center Research Ethics Board Written consent.

\section{AUTHOR CONTRIBUTIONS}

LF and ST performed the analyses. ST primarily wrote the manuscript. All authors participated in iterative revisions of the manuscript and participated in the conception and design of the analysis.

\section{FUNDING}

This study was funded in part by the Ontario Mental Health Foundation (OMHF) and the Canadian Institutes of Health Research (CIHR).

\section{ACKNOWLEDGMENTS}

We would like to acknowledge the contribution of the staff at the Centre for Youth Bipolar Disorder at Sunnybrook Health Sciences Centre, and thank the adolescents and their families for their participation.

8. Schulze TG, Hedeker D, Zandi P, Rietschel M, McMahon FJ. What is familial about familial bipolar disorder? Resemblance among relatives across a broad spectrum of phenotypic characteristics. Arch Gen Psychiatry (2006) 63:136876. doi: 10.1001/archpsyc.63.12.1368

9. Goldstein BI. Bipolar disorder and the vascular system: mechanisms and new prevention opportunities. Can J Cardiol. (2017) 33:1565-76. doi: 10.1016/j.cjca.2017.10.006

10. Swartz $\mathrm{H}$ a, Fagiolini A. Cardiovascular disease and bipolar disorder: risk and clinical implications. J Clin Psychiatry (2012) 73:1563-5. doi: $10.4088 /$ JCP.12ac08227

11. Goldstein BI, Carnethon MR, Matthews KA, McIntyre RS, Miller GE, Raghuveer G, et al. Major depressive disorder and bipolar disorder predispose youth to accelerated atherosclerosis and early cardiovascular disease: a scientific statement from the American Heart Association. Circulation (2015) 132:965-86. doi: 10.1161/CIR.00000000000 00229

12. Ösby U, Brandt L, Correia N, Ekbom A, Sparén P. Excess mortality in bipolar and unipolar disorder in Sweden. Arch Gen Psychiatry (2001) 58:844. doi: 10.1001/archpsyc.58.9.844

13. Angst F, Stassen HH, Clayton PJ, Angst J. Mortality of patients with mood disorders: follow-up over 34-38 years. J Affect Disord. (2002) 68:167-81. doi: 10.1016/S0165-0327(01)00377-9

14. Correll CU, Solmi M, Veronese N, Bortolato B, Rosson S, Santonastaso P, et al. Prevalence, incidence and mortality from cardiovascular disease in patients with pooled and specific severe mental illness: a large-scale metaanalysis of 3,211,768 patients and 113,383,368 controls. World Psychiatry (2017) 16:163-80. doi: 10.1002/wps.20420 
15. Carra G, Bartoli F, Carretta D, Crocamo C, Bozzetti A, Clerici M, et al. The prevalence of metabolic syndrome in people with severe mental illness: a mediation analysis. Soc Psychiatry Psychiatr Epidemiol. (2014) 49:1739-46. doi: 10.1007/s00127-014-0835-y

16. Westman J, Hällgren J, Wahlbeck K, Erlinge D, Alfredsson L, Osby U. Cardiovascular mortality in bipolar disorder: a population-based cohort study in Sweden. BMJ Open (2013) 3:e002373. doi: 10.1136/bmjopen-2012002373

17. Kilbourne AM, Cornelius JR, Han X, Pincus HA, Shad M, Salloum I, et al. Burden of general medical conditions among individuals with bipolar disorder. Bipolar Disord. (2004) 6:368-73. doi: 10.1111/j.1399-5618.2004.00138.x

18. Weeke A, Juel K, Væth M. Cardiovascular death and manicdepressive psychosis. J Affect Disord. (1987) 13:287-92. doi: 10.1016/0165-0327(87)90049-8

19. Goldstein BI, Schaffer A, Wang S, Blanco C. Excessive and premature new-onset cardiovascular disease among adults with bipolar disorder in the US NESARC cohort. J Clin Psychiatry (2015) 76:163-9. doi: 10.4088/JCP.14m09300

20. Fiedorowicz J. Elevated prevalence of obesity, metabolic syndrome, and cardiovascular risk factors in bipolar disorder. Ann Clin. (2008) 20:131-7. doi: 10.1080/10401230802177722.Elevated

21. Cardenas J, Frye MA, Marusak SL, Levander EM, Chirichigno JW, Lewis $\mathrm{S}$, et al. Modal subcomponents of metabolic syndrome in patients with bipolar disorder. J Affect Disord. (2008) 106:91-7. doi: 10.1016/j.jad.2007. 05.030

22. Johannessen L, Strudsholm U, Foldager L, Munk-Jorgensen P. Increased risk of hypertension in patients with bipolar disorder and patients with anxiety compared to background population and patients with schizophrenia. J Affect Disord. (2006) 95:13-7. doi: 10.1016/j.jad.2006. 03.027

23. Kraepelin E. Manic-Depressive Insanity and Paranoia. Edinburgh: E.S. Livingstone (1921).

24. Tsuang MT, Woolson RF, Fleming JA. Causes of death in schizophrenia and manic-depression. Br J Psychiatry (1980) 136:239-42. doi: 10.1192/bjp.136.3.239

25. Goldstein BI, Fagiolini A, Houck P, Kupfer DJ. Cardiovascular disease and hypertension among adults with bipolar I disorder in the United States. Bipolar Disord. (2009) 11:657-62. doi: 10.1111/j.1399-5618.2009.00735.x

26. Sobczak S, Honig A, Christophe M, Maes M, Helsdingen RWC, De Vriese $\mathrm{S}$, et al. Lower high-density lipoprotein cholesterol and increased omega-6 polyunsaturated fatty acids in first-degree relatives of bipolar patients. Psychol Med. (2004) 34:103-12. doi: 10.1017/S0033291703001090

27. Mothi SS, Tandon N, Padmanabhan J, Mathew IT, Clementz B, Tamminga $\mathrm{C}$, et al. Increased cardiometabolic dysfunction in first-degree relatives of patients with psychotic disorders. Schizophr Res. (2015) 165:103-7. doi: 10.1016/j.schres.2015.03.034

28. Baptista T, Sandia I, Fernandez E, Balzá L, Connell L, Uzcá E, et al. Metabolic syndrome and related variables, insulin resistance, leptin levels, and PPAR-c2 and leptin gene polymorphisms in a pedigree of subjects with bipolar disorder. Rev Bras Psiquiatr. (2015)106-12. doi: 10.1590/1516-4446-2014-1425

29. Lee KE, Klein BE, Klein R. Familial aggregation of components of the multiple metabolic syndrome in the Framingham Heart and Offspring Cohorts: genetic analysis workshop Problem 1. BMC Genet. (2003) 4:S94. doi: 10.1186/1471-2156-4-S1-S94

30. Sabo RT, Lu Z, Deng X, Ren C, Daniels S, Arslanian S, et al. Parental and offspring associations of the metabolic syndrome in the Fels Longitudinal Study. Am J Clin Nutr. (2012) 96:461-6. doi: 10.3945/ajcn.111.025635

31. Liese AD, Mayer-Davis EJ, Tyroler HA, Davis CE, Keil U, Schmidt MI, et al. Familial components of the multiple metabolic syndrome: The ARIC study. Diabetologia (1997) 40:963-70. doi: 10.1007/s001250050775

32. Burke GL, Savage PJ, Sprafka JM, Selby JV, Jacobs DR, Perkins LL, et al. Relation of risk factor levels in young adulthood to parental history of disease. The CARDIA study. Circulation (1991) 84:1176-87. doi: 10.1161/01.CIR.84.3.1176

33. Rasgon NL, Kenna HA, Reynolds-May MF, Stemmle PG, Vemuri M, Marsh W, et al. Metabolic dysfunction in women with bipolar disorder: the potential influence of family history of type 2 diabetes mellitus. Bipolar Disord. (2010) 12:504-13. doi: 10.1111/j.1399-5618.2010.00839.x

34. Kaufman J, Birmaher B, Brent D, Rao U, Flynn C, Moreci P et al. Schedule for affective disorders and schizophrenia for school-age children-present and lifetime version (K-SADS-PL): initial reliability and validity data. J Am Acad Child Adolesc Psychiatry (1997) 7:980-8.

35. Chambers WJ, Puig-Antich J, Hirsch M, Paez P, Ambrosini PJ, Tabrizi MA, et al. The assessment of affective disorders in children and adolescents by semistructured interview. Test-retest reliability of the schedule for affective disorders and schizophrenia for school-age children, present episode version. Arch Gen Psychiatry (1985) 42:696-702. doi: 10.1001/archpsyc.1985.01790300 064008

36. Axelson D, Birmaher BJ, Brent D, Wassick S, Hoover C, Bridge J, et al. A preliminary study of the Kiddie Schedule for Affective Disorders and Schizophrenia for School-Age Children mania rating scale for children and adolescents. J Child Adolesc Psychopharmacol. (2003) 13:463-70. doi: 10.1089/104454603322724850

37. Axelson D, Birmaher B, Strober M, Gill MK, Valeri S, Chiappetta L, et al. Phenomenology of children and adolescents with bipolar spectrum disorders. Arch Gen Psychiatry (2006) 63:1139-48. doi: 10.1001/archpsyc.63.10.1139

38. American Psychiatric Association. Diagnostic and Statistical Manual for Mental Disorders. 4th ed. Washington, DC: American psychiatric publishing (1994).

39. Shaffer D, MS G, Brasic J, Al E. A children's global assessment scale (cgas). Arch Gen Psychiatry (1983) 40:1228-31. doi: 10.1001/archpsyc.1983.01790100074010

40. Hollingshead A. Four factor index of social status. Yale J Sociol. (2011) $8: 21-53$.

41. Weissman MM. Brief screening for family psychiatric history: the family history screen. Arch Gen Psychiatry (2000) 57:675-82. doi: 10.1001/archpsyc.57.7.675

42. Friedman GD, Cutter GR, Donahue RP, Hughes GH, Hulley SB, Jacobs $\mathrm{DR}$, et al. Cardia: study design, recruitment, and some characteristics of the examined subjects. J Clin Epidemiol. (1988) 41:1105-16. doi: 10.1016/0895-4356(88)90080-7

43. Islam AH, Metcalfe AWS, MacIntosh BJ, Korczak DJ, Goldstein BI. Greater body mass index is associated with reduced frontal cortical volumes among adolescents with bipolar disorder. J Psychiatry Neurosci. (2018) 43:120-30. doi: 10.1503/jpn.170041

44. Kuczmarski RJ, Ogden CL, Grummer-Strawn LM, Flegal KM, Guo SS, Wei R, et al. CDC growth charts: United States. Adv Data (2000) 8:1-27.

45. Baldessarini RJ, Tondo L, Vazquez GH, Undurraga J, Maffei PM, Salvatore $\mathrm{P}$, et al. Age at onset versus family history and clinical outcomes in 1,665 international bipolar-I disorder patients. World Psychiatry (2012) 11:40-6. doi: 10.1016/j.wpsyc.2012.01.006

46. Amare AT, Schubert KO, Klingler-Hoffmann M, Cohen-Woods S, Baune BT. The genetic overlap between mood disorders and cardiometabolic diseases: a systematic review of genome wide and candidate gene studies. Transl Psychiatry (2017) 7:e1007. doi: 10.1038/tp.20 16.261

47. Young DR, Hivert M-F, Alhassan S, Camhi SM, Ferguson JF, Katzmarzyk PT, et al. Sedentary behavior and cardiovascular morbidity and mortality: a science advisory from the American Heart Association. Circulation (2016) 134:e262-79. doi: 10.1161/CIR.00000000000 00440

48. Rasic D, Hajek T, Alda M, Uher R. Risk of mental illness in offspring of parents with schizophrenia, bipolar disorder, and major depressive disorder: a meta-analysis of family high-risk studies. Schizophr Bull. (2014) 40:28-38. doi: $10.1093 /$ schbul/sbt114

49. Post RM, Altshuler L, Kupka R, McElroy SL, Frye MA, Rowe M, et al. Multigenerational positive family history of psychiatric disorders is associated with a poor prognosis in bipolar disorder. J Neuropsychiatry Clin Neurosci. (2015) 27:304-10. doi: 10.1176/appi.neuropsych.140 80204

50. Antypa N, Serretti A. Family history of a mood disorder indicates a more severe bipolar disorder. J Affect Disord. (2014) 156:178-86. doi: 10.1016/j.jad.2013.12.013 
51. Fiedorowicz JG, Solomon DA, Endicott J, Leon AC, Li C, Rice JP, et al. Manic/hypomanic symptom burden and cardiovascular mortality in bipolar disorder. Psychosom Med. (2009) 71:598-606. doi: 10.1097/PSY.0b013e3181 acee 26

52. Fiedorowicz JG, Jancic D, Potash JB, Butcher B, Coryell WH. Vascular mortality in participants of a bipolar genomics study. Psychosomatics (2014) 55:485-90. doi: 10.1016/j.psym.2014.02.001

53. Fiedorowicz JG, Coryell WH, Rice JP, Warren LL, Haynes WG. Vasculopathy related to manic/hypomanic symptom burden and first-generation antipsychotics in a sub-sample from the collaborative depression study. Psychother Psychosom. (2012) 81:235-43. doi: 10.1159/000334779

54. Ruzickova M, Slaney C, Garnham J, Alda M. Clinical features of bipolar disorder with and without comorbid diabetes mellitus. Can J Psychiatry (2003) 48:458-61. doi: 10.1177/070674370304800705

55. Kemp DE, Gao K, Chan PK, Ganocy SJ, Findling RL, Calabrese JR. Medical comorbidity in bipolar disorder: Relationship between illnesses of the endocrine/metabolic system and treatment outcome. Bipolar Disord. (2010) 12:404-13. doi: 10.1111/j.1399-5618.2010.00823.x

56. McIntyre RS, Konarski JZ, Soczynska JK, Wilkins K, Panjwani G, Bouffard $\mathrm{B}$, et al. Medical comorbidity in bipolar disorder: Implications for functional outcomes and health service utilization. Psychiatr Serv. (2006) 57:1140-4. doi: 10.1176/appi.ps.57.8.1140

57. Cuellar-Barboza AB, Winham SJ, Mcelroy SL, Geske JR, Jenkins GD, Colby CL, et al. Accumulating evidence for a role of TCF7L2 variants in bipolar disorder with elevated body mass index. Bipolar Disord. (2016) 18:124-35. doi: $10.1111 /$ bdi. 12368

58. Ou X, Crane DE, MacIntosh BJ, Young LT, Arnold P, Ameis S, et al. CACNA1C rs1006737 genotype and bipolar disorder: Focus on intermediate phenotypes and cardiovascular comorbidity. Neurosci Biobehav Rev. (2015) 55:198-210. doi: 10.1016/j.neubiorev.2015.04.022

59. Goldstein BI, Kemp DE, Soczynska JK, McIntyre RS. Inflammation and the phenomenology, pathophysiology, comorbidity, and treatment of bipolar disorder: a systematic review of the literature. J Clin Psychiatry (2009) 70:1078-90. doi: 10.4088/JCP.08r04505

60. Rosenblat JD, McIntyre RS. Bipolar disorder and inflammation. Psychiatr Clin North Am. (2016) 39:125-37. doi: 10.1016/j.psc.2015.09.006

61. Leboyer M, Soreca I, Scott J, Frye M, Henry C, Tamouza R, et al. Can bipolar disorder be viewed as a multi-system inflammatory disease? J Affect Disord. (2012) 141:1-10. doi: 10.1016/j.jad.2011.12.049

62. Padmos RC, Hillegers MHJ, Knijff EM, Vonk R, Bouvy A, Staal FJT, et al. A Discriminating messenger RNA signature for bipolar disorder formed by an aberrant expression of inflammatory genes in monocytes. Arch Gen Psychiatry (2008) 65:395. doi: 10.1001/archpsyc.65.4.395

63. Rosenblat JD, McIntyre RS. Bipolar disorder and immune dysfunction: epidemiological findings, proposed pathophysiology and clinical implications. Brain Sci. (2017) 7:E144 doi: 10.3390/brainsci7110144

64. Eckel RH, Grundy SM, Zimmet PZ. The metabolic syndrome. Lancet (2005) 42:524-7. doi: 10.1258/jrsm.99.9.457

65. Willerson JT, Ridker PM. Inflammation as a cardiovascular risk factor. Circulation (2004) 109(21 Suppl. 1):II2-10. doi: 10.1161/01.cir.0000129535.04194.38

66. Dandona P, Aljada A, Chaudhuri A, Mohanty P, Garg R. Metabolic syndrome: a comprehensive perspective based on interactions between obesity, diabetes, and inflammation. Circulation (2005) 111:1448-54. doi: 10.1161/01.CIR.0000158483.13093.9D

67. Sharma AN, Bauer IE, Sanches M, Galvez JF, Zunta-Soares GB, Quevedo J, et al. Common biological mechanisms between bipolar disorder and type 2 diabetes: focus on inflammation. Prog Neuropsychopharmacol Biol Psychiatry (2014) 54:289-98. doi: 10.1016/j.pnpbp.2014.06.005

68. Leddy MA, Power ML, Schulkin J. The impact of maternal obesity on maternal and fetal health. Rev Obstet Gynecol. (2008) 1:170-8. doi: 10.1111/ajo. 12253

69. Geelhoed JJM, Fraser A, Tilling K, Benfield L, Davey Smith G, Sattar $\mathrm{N}$, et al. Preeclampsia and gestational hypertension are associated with childhood blood pressure independently of family adiposity measures: the avon longitudinal study of parents and Children. Circulation (2010) 122:1192-9. doi: 10.1161/CIRCULATIONAHA.110. 936674
70. Maher GM, O'Keeffe GW, Kearney PM, Kenny LC, Dinan TG, Mattsson $\mathrm{M}$, et al. Association of hypertensive disorders of pregnancy with risk of neurodevelopmental disorders in offspring. JAMA Psychiatry (2018) 75:80919. doi: 10.1001/jamapsychiatry.2018.0854

71. Van Lieshout RJ, Taylor VH, Boyle MH. Pre-pregnancy and pregnancy obesity and neurodevelopmental outcomes in offspring: a systematic review. Obes Rev. (2011) 12:e548-59. doi: 10.1111/j.1467-789X.2010. 00850.x

72. Rusner M, Berg M, Begley C. Bipolar disorder in pregnancy and childbirth: a systematic review of outcomes. BMC Pregnancy Childbirth (2016) 16:331. doi: 10.1186/s12884-016-1127-1

73. Perusse L, Leblanc C, Tremblay A, Allard C, Theriault G, Landry F, et al. Familial aggregation in physical fitness, coronary heart disease risk factors, and pulmonary function measurements. Prev Med. (1987) 16: 607-15.

74. Jacobi D, Caille A, Borys JM, Lommez A, Couet C, Charles MA, et al. Parentoffspring correlations in pedometer-assessed physical activity. PLoS ONE (2011) 6:e29195. doi: 10.1371/journal.pone.0029195

75. Janney CA, Fagiolini A, Swartz HA, Jakicic JM, Holleman RG, Richardson CR. Are adults with bipolar disorder active? Objectively measured physical activity and sedentary behavior using accelerometry. J Affect Disord. (2014) 152-4:498-504. doi: 10.1016/j.jad.2013.09.009

76. Cairney J, Veldhuizen S, Faulkner G, Schaffer A, Rodriguez MC. Bipolar disorder and leisure-time physical activity: results from a national survey of Canadians. Ment Health Phys Act. (2009) 2:65-70. doi: 10.1016/j.mhpa.2009.09.003

77. Kilbourne AM, Rofey DL, Mccarthy JF, Post EP, Welsh D, Blow FC. Nutrition and exercise behavior among patients with bipolar disorder. Bipolar Disord. (2007) 9:443-52. doi: 10.1111/j.1399-5618.2007.00386.x

78. Vancampfort D, Firth J, Schuch F, Rosenbaum S, De Hert M, Mugisha J, et al. Physical activity and sedentary behavior in people with bipolar disorder: a systematic review and meta-analysis. J Affect Disord. (2016) 201:145-52. doi: 10.1016/j.jad.2016.05.020

79. Melo MCA, Daher EDF, Albuquerque SGC, De Bruin VMS. Exercise in bipolar patients: a systematic review. J Affect Disord. (2016) 198:32-8. doi: 10.1016/j.jad.2016.03.004

80. Jewell L, Abtan R, Scavone A, Timmins V, Swampillai B, Goldstein BI. Preliminary evidence of disparities in physical activity among adolescents with bipolar disorder. Ment Health Phys Act. (2015) 8:62-7. doi: 10.1016/j.mhpa.2015.04.001

81. Biswas A, Oh PI, Faulkner GE, Bajaj RR, Silver MA, Mitchell MS, et al. Sedentary time and its association with risk for disease incidence, mortality and hospitalization in adults a systematic review and meta-analysis. Ann Intern Med. (2015) 162:123-32. doi: 10.7326/M14-1651

82. Stubbe JH, Boomsma DI, Vink JM, Cornes BK, Martin NG, Skytthe A, et al. Genetic influences on exercise participation in 37.051 twin pairs from seven countries. PLOS ONE (2006) 1:e22. doi: 10.1371/journal.pone. 0000022

83. Fisher A, Smith L, van Jaarsveld CHM, Sawyer A, Wardle J. Are children's activity levels determined by their genes or environment? A systematic review of twin studies. Prev Med Rep. (2015) 2:548-53. doi: 10.1016/j.pmedr.2015.06.011

84. Kandel DB, Griesler PC, Hu MC. Intergenerational patterns of smoking and nicotine dependence among US adolescents. Am J Public Health (2015) 105:e63-72. doi: 10.2105/AJPH.2015. 302775

85. Mays D, Gilman SE, Rende R, Luta G, Tercyak KP, Niaura RS. Parental smoking exposure and adolescent smoking trajectories. Pediatrics (2014) 133:983-91. doi: 10.1542/peds.2013-3003

86. Ziedonis D, Hitsman B, Beckham JC, Zvolensky M, Adler LE, Audrain-McGovern J, et al. Tobacco use and cessation in psychiatric disorders: National Institute of Mental Health report. Nicotine Tob Res. (2008) 10:1691-715. doi: 10.1080/146222008024 43569

87. Diaz FJ, James D, Botts S, Maw L, Susce MT, De Leon J. Tobacco smoking behaviors in bipolar disorder: a comparison of the general population, schizophrenia, and major depression. Bipolar Disord. (2009) 11:154-65. doi: 10.1111/j.1399-5618.2009.00 664.x 
88. Suglia SF, Koenen KC, Boynton-Jarrett R, Chan PS, Clark CJ, Danese $\mathrm{A}$, et al. Childhood and adolescent adversity and cardiometabolic outcomes: a scientific statement from the American Heart Association. Circulation (2018) 137:e15-28. doi: 10.1161/CIR.00000000000 00536

89. Danese A, Moffitt TE, Harrington HL, Milne BJ, Polanczyk G, Pariante CM, et al. Adverse childhood experiences and adult risk factors for age-related disease: depression, inflammation, and clustering of metabolic risk markers. Arch Pediatr Adolesc Med. (2009) 163:1135-43. doi: 10.1001/archpediatrics.20 09.214

90. Anda RF, Felitti VJ, Bremner JD, Walker JD, Whitfield C, Perry BD, et al. The enduring effects of abuse and related adverse experiences in childhood: a convergence of evidence from neurobiology and epidemiology. Eur Arch Psychiatry Clin Neurosci. (2006) 256:174-86. doi: 10.1007/s00406-0050624-4

91. Tyrka AR, Price LH, Marsit C, Walters OC, Carpenter LL. Childhood adversity and epigenetic modulation of the leukocyte glucocorticoid receptor: preliminary findings in healthy adults. PLoS ONE (2012) 7:e30148. doi: 10.1371/journal.pone.0030148

92. Roth TL, Lubin FD, Funk AJ, Sweatt JD. Lasting epigenetic influence of early-life adversity on the BDNF gene. Biol Psychiatry (2009) 65:760-9. doi: 10.1016/j.biopsych.2008.11.028

Conflict of Interest Statement: The authors declare that the research was conducted in the absence of any commercial or financial relationships that could be construed as a potential conflict of interest.

Copyright (c) 2019 Toma, Fiksenbaum, Omrin and Goldstein. This is an open-access article distributed under the terms of the Creative Commons Attribution License (CC BY). The use, distribution or reproduction in other forums is permitted, provided the original author(s) and the copyright owner(s) are credited and that the original publication in this journal is cited, in accordance with accepted academic practice. No use, distribution or reproduction is permitted which does not comply with these terms. 